\title{
LITTLE WOODBATCH, MARKET GARDEN: AN INTERVIEW WITH DAPHNE PAGE, BISHOP'S CASTLE, UK
}

\author{
Interviewed by Keith Whiddon
}

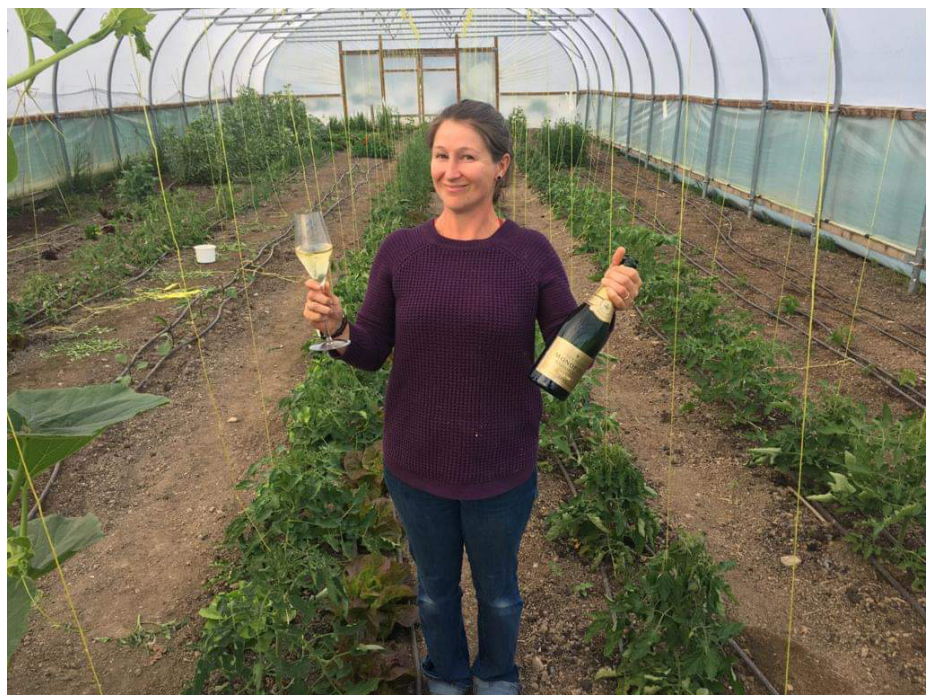

Figure I. Daphne Page. Source: Daphne Page

Keith: Tell me about your background Daphne?

Daphne: I came from Canada having done a master's in environmental science and what I focused on there was rooftop agriculture in the city of Toronto. I was offered a place at the Centre for Food Policy in London to do a $\mathrm{PhD}$, focusing on food policies being developed in the UK with a focus on how civil society groups and the local councils are coming together and in different partnership models, looking at how these different partnership models come together to make local food policy that is about sustainable food production. So that is urban, rural and everything in between, and how these groups are working together to varying degrees of success to make these initiatives happen.

Keith: Can you tell me about your Market Garden?

Daphne: Little Woodbatch is a direct result of my research into sustainable food production and personal disenchantment with the conventional food system. It is something that I felt could be a way to not only live according to our values as a family and get closer to means of food production that we agree with, but also a way to do it right in practice. So integrate a number of different elements of sustainability, beyond simply 
environmental, economic and social, but it can be about so many aspects of food, which are becoming a more a part of the dialogue of sustainability and the food system and it's an educational tool. It's a place where people can get together and we're going to be teaching different ways of sustainable food production, be it composting, be it how to plan your allotment, storing food. So we're going to be working on a course catalogue for the coming year in order to branch out into that educational aspect of the farm.

We are a one acre market garden in the town of Bishop's Castle and the only market garden. There are a couple of other ones that are nearby, but we are the only one who has specifically focused on serving our local community. We have made a deliberate choice not to branch out to the wider region simply because we want to try to support our community with short food supply chains, which is a big initiative that is discussed in sustainability and food systems literature. So not shipping things in from all over the place, reducing carbon and making sure were a part of our community first.

Keith: How long has it taken you to develop Little Woodbatch?

Daphne: We are in our third year, we started out with simply providing for a shop and a local restaurant or two, and that expanded into about four different restaurants, veggie boxes, farmers markets and a shop. And now with the pandemic, with restaurants and farmer's markets closed, we're now focused on expanding our veggie box offering to a wider range in the community and selling to shops as well and we're also giving to our local food bank every week.

Keith: Your philosophy is one of sustainable local food systems - why is this important to you?

Daphne: It's important to me because the conventional food system has been since the 1970s, based on the philosophy of more production, and lower prices, and it's ultimately based on exploitation of people, of resources and distancing us from the way that our food is produced, and we don't see the negative impacts. The costs are externalised in a way that we aren't aware of-just how heavily the earth and people producing our food are being impacted. We're addressing this by re-localising and producing our food at a human scale, a small-scale mixed farm with a focus on soil ecology and non-chemical production.

We have a way of taking care of the people who work here, of the environment that we're working in, and the community, so that that big production mentality is turned on its head. The concept is that small is beautiful, small is adaptable, where big production is not. With the pandemic, for example, we were able to turn on a dime, change what we were going to be growing, change how much we were going to be growing so we would be able to serve more people. Whereas you wouldn't get that with a 'big ag' conventional farm that is focused on planting one thing for the entire year.

So it's important to us in in so many ways - it's political, it's environmental, it's based on our values. It's based on our desire to connect people with their food and to reintegrate people's relationships with who produces their food, how their food is produced and to build an awareness. That is, again, turning the conventional food system on its head where that distance is now a closeness, a connection.

Keith: Your original thinking was about how we needed to prepare for the effects of a food shortage due to a no-deal Brexit by developing local food production. Did this prepare you for the current pandemic crisis and if so in what ways?

Daphne: I think as a result of my research my awareness of the sensitivity of our food supply chains and the fragility of those is probably heightened. My research centre began putting out policy briefings on the things that our government hasn't been acknowledging, or at least not publicly acknowledging, in terms of the fragility of our supply chains in the event of a no-deal Brexit, where supply chains are expected to be interrupted due to 
the inability of lorries to get to the country, or line-ups at borders. So supply chain disruptions as well as pricing increases which would affect the population are expected and would have significant impacts on the population.

These things are going to be realities for the UK in whatever upcoming Brexit scenario, so in a sense, we've had a dry run with the pandemic, haven't we? We have seen supply chain disruption first-hand and I think it's made the population realise that we are still vulnerable. We do still live in a just-in-time food system. Just because we are a wealthy country, doesn't mean that we are impervious to these impacts. The UK has been like most wealthy countries - it has always had the view that someone else will feed us. That was the UK's pre-wartime view that got interrupted and it has been the case since and so this sort of privileged view that somebody else will come to our rescue and feed us, was shaken.

There's been, in my experience as a farmer, a great recognition of the importance of local food and locally accessible food. We've seen a huge surge in interest in our food production at the farm. But I think people have realised that there's been quite a lot that they've taken for granted in terms of the conventional food system. So, in a sense, I think people are going to be a lot more wary of no-deal Brexit and Brexit deals that don't have a strong inclination towards food and food security.

Reading a book from one of my advisors recently on issues with the UK food system [Tim Lang, Feeding Britain: Our Food Problems and How to Fix Them, 2020)] Tim Lang has made the point that after the 2007-2008 financial crisis, where there was inflation, there were food riots even in wealthy countries. People quickly forgot and went back to normal and normal ways of consumption. I'm hoping that this isn't that situation repeated. I think this pandemic will leave a big mark on our cultural memory.

Keith: What are you doing to help the local community through the pandemic crisis?

Daphne: Our initial plan this year was to focus on veggie boxes and do a small number. As we began to really hone our efficiency on the farm, then the pandemic came along, and we realised that our responsibility was to scale up production and to feed as many people as we could. In February, when we were starting our seeding, we had no idea how extensive the threat would be and how much the national food situation would be disrupted.

We just went completely overboard which was, I think the right move. We also increased our veggie box list. Currently we are at 30 weekly veggie boxes but we're going to be opening that

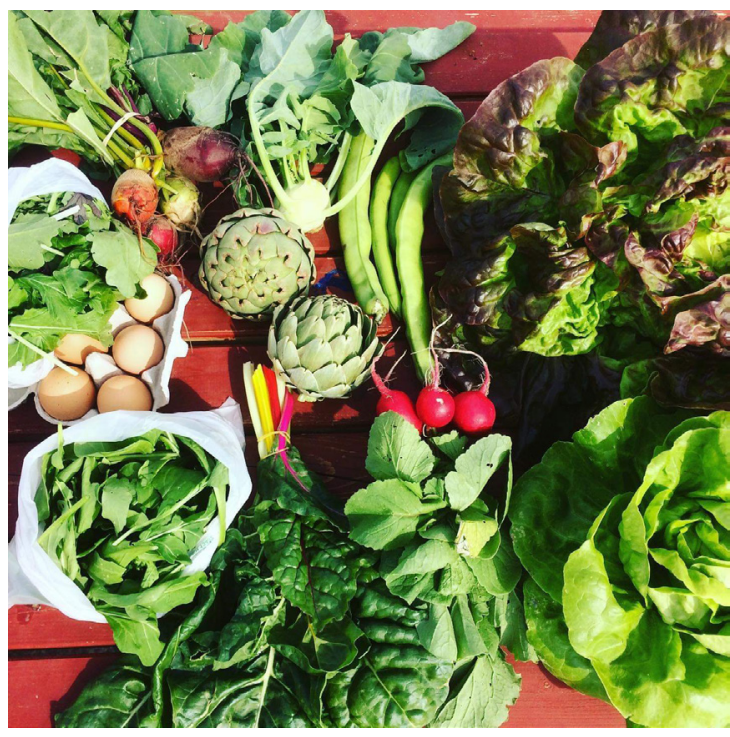

Figure 2. Food Box. Source: Daphne Page up to another 10. In the coming week we will provide to a local, independent shop, 'Harvest Whole Foods' where we're supplying salads and vegetables every week. They have seen a surge in in demand as well as people want to shop from small local places rather than chain food supply stores.

The one thing that we had initially thought we would do is a 'sponsor a veggie box' initiative. So the idea behind that would be our veggie box customers would be able to purchase an additional box which we would be able to allocate to someone in need. The ethical dilemma there is how do we identify who is most in need? That brought 
in a whole level that we weren't comfortable with and was resolved by our partnership with the Bishop's Castle Food Bank, which was created as a response to the pandemic. Previously, we just had the Clun Food Bank, but now, this has emerged as a local food bank running two days a week.

We realised that everybody is under pressure right now, in a number of ways, but financial is one of them, so asking more of our veggie box customers we felt was unfair. So we scrapped the sponsor a veggie box initiative and we're simply donating all of our surplus on a regular basis each week. We have volunteers who come and help with harvesting, and then we take it to the food bank on a Thursday. They keep in touch with us and let us know how many people they've had every week. It started out with one person, and it has gone up to about 50 currently in the past week, and more people receiving deliveries through the food bank, so they get packages, including our veggies.

What distinguishes our local food bank is that they will take fresh food, whereas most will not-for example neither the UK Trussell Trust nor the Clun Food Bank will take any fresh veg. So it's been a really wonderful partnership because we are producing an excess right now for the amount of veggie boxes that we're doing, but it allows us an outlet for it still to be used and it's donated fully by us at this point.

I think that adaptability and resilience is what keeps the community and also spirits afloat. I've been seeing what a few chefs are doing locally, creating nice things to deliver. We've effectively become a small food hub where we've partnered with a few local producers - a friend who does cut flowers, a friend who has a brewery and a friend who bakes and does bread whose restaurant is closed due to lockdown. We have added these elements to our veggie box offering and also increased our own flock of chickens so that we can provide eggs. These are little adaptations that people have made and we are able to be a hub for distribution for our veggie box customers. That is definitely one thing that I think we'll be keeping, because if we can be a one-stop shop for people's basic grocery needs, I think that is something advantageous to us and the people who are producers and makers around us in our community.

Keith: What are your future plans when the current pandemic crisis is over? Where do you see yourself and Little Woodbatch in 5 to 10 years' time?

Daphne: Future plans are to continue scaling up our veggie box offering as a part of that expanding to increase access or accessibility, because currently, it's largely retired middle class people who are fairly comfortable financially. We want to make sure that good healthy local food is accessible to all, so finding a way to connect with members of the community. For example, families whose children are on free school meals, elderly and vulnerable people - how we can reach them as well and make our veg affordable and accessible to people who struggle as a demographic to access and eat healthy veg on a regular basis. So one element is to increase accessibility, increase our production and efficiency.

We would like to continue to hire more local people so as we are able to do more veggie boxes, for example, which is going to be our main area of focus. We enjoy supplying our local restaurants, we enjoy supplying shops. The thing that we enjoy most is connecting with individuals and veggie boxes are really the way to have relationships through this. We have a really exceptional community of creative, caring people who are very supportive of what we're doing and it's been a pleasure to get to know them as individuals. We would like to eventually triple our veggie box offerings so that we're closer to 100 veggie boxes from one acre.

We would like to expand the amount of land we have, so that we would be able to create more socially accessible initiatives like a community forest garden. Also, a growing space for local schools, where they would be able to come. That sort of parallels our desire to make this an educational hub for food and growing. We've been in 
discussion with the local college and the local school prior to the pandemic shutdown, about getting them here. For us to be able to share this, because my experience as an educator couples really with the practical element of what we're doing.

In the next five years, I see us having a course offering, I see us potentially having more land that we're developing into the broader sustainability initiative that we have, with more of a focus on agri-ecology, and rewilding sections of our land, the land around us, which is currently being used for conventional agriculture. I think my academic life is going to run parallel to that as well. We have a couple of agricultural universities around here. So publishing the experiences of Little Woodbatch and our links with the community is going to be an important part of what I would like to continue to do. In 10 years, hopefully we have a property maturing around us and ponds teeming with wildlife and soil teeming with microbes and a community that sees us as something that has brightened it and broadened it and informed it and created a space where it can come and thrive and participate. A community that sees us as having contributed to the resilience of the town through good times and bad.

Daphne Page holds a PhD in Food Policy from The Centre for Food Policy, City University of London. Her research is focused on the partnerships involved in creating community-level sustainable food policies in the UK. As a result of this research, she founded Little Woodbatch Market Garden in the town of Bishop's Castle in 2017.

Correspondence to: Daphne Page. Email: daphne.page@city.ac.uk 